\title{
Commentary on "Brain Temperature Influences Intracranial Pressure and Cerebral Perfusion Pressure After Traumatic Brain Injury"
}

\author{
Benjamin Elstrott ${ }^{1}$ and H. E. Hinson ${ }^{2^{*}}$ (1) \\ C 2021 Springer Science+Business Media, LLC, part of Springer Nature and Neurocritical Care Society
}

\begin{abstract}
Although it is well established that fever is associated with prolonged intensive care unit stays and higher patient mortality rates $[1,2]$ following traumatic brain injury (TBI), it remains unclear whether fever is the driver of harm or a bystander. Elevated temperatures may act as the mechanism for cellular injury, and thus patient deterioration, or, alternatively, fever might denote the presence of a separate process responsible for both pyrexia and injury. There are multiple mechanisms by which posttraumatic fever has been proposed to intensify central nervous system cellular injury, although, in humans, only indirect evidence exists of secondary injury during fever [3]. Regardless, the standard of care is to monitor temperature and treat fever when it arises in patients with brain injury. Conventionally, core body temperature measured from the bladder or esophagus is often used as a surrogate for brain temperature. However, as it becomes increasingly feasible to directly measure brain temperature with invasive monitors, clinicians and researchers struggle to interpret and act on this new data. Although brain temperature usually correlates tightly with core temperature at $0.5-1{ }^{\circ} \mathrm{C}$ higher [4], core and brain temperatures may decouple in certain circumstances that are incompletely understood [5].

In this issue of Neurocritical Care, Birg and colleagues [6] retrospectively analyzed a subgroup of 21 patients enrolled in the CENTER-TBI study, in whom brain
\end{abstract}

\footnotetext{
*Correspondence: hinson@ohsu.edu

${ }^{2}$ Departments of Neurology and Emergency Medicine, Oregon Health and Science University, 3181 SW Sam Jackson Park Road, CR-127, Portland, OR 97239, USA

Full list of author information is available at the end of the article
}

temperature, intracranial pressure (ICP), and cerebral perfusion pressure $(\mathrm{CPP})$ were concurrently monitored to characterize the relationship between brain temperature, ICP, and CPP. The authors observed that elevated brain temperature $\left(>38.0^{\circ} \mathrm{C}\right)$ after TBI is common and that during episodes of elevated brain temperature (particularly during acute elevations), the ICP and CPP deteriorated. This observation is reciprocal to prior observations that induction of normothermia or hypothermia can lower ICP $[7,8]$ and provides an important contribution to our understanding of the relationship between temperature and secondary brain injury.

However, there are some missed opportunities in the current work. One of the more crucial gaps in our comprehension of fever after TBI is the degree to which core body and brain temperatures correlate and if core temperature is truly an adequate surrogate for brain temperature. Unfortunately, this investigation was unable to yield high resolution body temperature data to compare against brain temperature, ICP, and CPP. Additionally, interventions for fever, such as antipyretic medications, were not captured. An exploration of the use and impact of antipyretics on brain temperature, ICP, and CPP would have been a valuable contribution to the ongoing dialogue concerning the benefits of fever control in patients with TBI. Furthermore, how do sedatives and anesthetics influence these variables? The authors consider that their use may be responsible for the biphasic relationship between brain temperature and ICP, as well as speculate that the magnitude change to ICP and CPP may have been more extreme in the absence of these therapies. Future studies should seek to quantify the effect that our therapies have on brain temperature. 
To advance the field, we must develop a better grasp on the root cause of the association between fever and secondary brain injury. The pathophysiology of brain temperature is almost certainly an essential character in this narrative. With increasingly widespread adoption of brain temperature monitoring and the tools to analyze high dimensional physiologic data from these monitors, we are likely on the cusp of such an understanding.

\section{Author details}

${ }^{1}$ School of Medicine, Oregon Health and Science University, Portland, OR, USA. ${ }^{2}$ Departments of Neurology and Emergency Medicine, Oregon Health and Science University, 3181 SW Sam Jackson Park Road, CR-127, Portland, OR 97239, USA.

\section{Source of support}

This work received no funding.

\section{Conflicts of interest}

Mr. Elstrott has no conflicts of interest. Dr. Hinson reports no relevant conflicts of interest.

\section{Publisher's Note}

Springer Nature remains neutral with regard to jurisdictional claims in published maps and institutional affiliations.

Received: 18 March 2021 Accepted: 9 June 2021

Published online: 30 July 2021

\section{References}

1. Bao $L$, Chen $D$, Ding $L$, Ling W, Xu F. Fever burden is an independent predictor for prognosis of traumatic brain injury. PLoS ONE. 2014;9:e90956.

2. Li J, Jiang J. Chinese Head Trauma Data Bank: effect of hyperthermia on the outcome of acute head trauma patients. J Neurotrauma. 2012;29:96-100.

3. Oddo M, Frangos S, Milby A, Chen I, Maloney-Wilensky E, Murtrie EM, et al. Induced normothermia attenuates cerebral metabolic distress in patients with aneurysmal subarachnoid hemorrhage and refractory Fever. Stroke. 2009;40:1913-6.

4. Henker RA, Brown SD, Marion DW. Comparison of brain temperature with bladder and rectal temperatures in adults with severe head injury. Neurosurgery. 1998:42:1071-5.

5. Childs C, Lunn KW. Clinical review: brain-body temperature differences in adults with severe traumatic brain injury. Crit Care. 2013;17:222.

6. Birg T, Ortolano T, Wiegers EJA, Smielewski P, Savchenko Y, Andrey lanosi $B$, et al. Brain temperature influences intracranial pressure and cerebral perfusion pressure after traumatic brain injury: a CENTER TBI study. Neurocrit Care. 2021. https://doi.org/10.1007/s12028-021-01294-1.

7. Puccio AM, Fischer MR, Jankowitz BT, Yonas H, Darby JM, Okonkwo DO. Induced normothermia attenuates intracranial hypertension and reduces fever burden after severe traumatic brain injury. Neurocrit Care. 2009;11:82-7.

8. Andrews PJ, Sinclair HL, Rodríguez A, Harris B, Rhodes J, Watson H, et al. Therapeutic hypothermia to reduce intracranial pressure after traumatic brain injury: the Eurotherm3235 RCT. Health Technol Assess. 2018;22:1-134. 